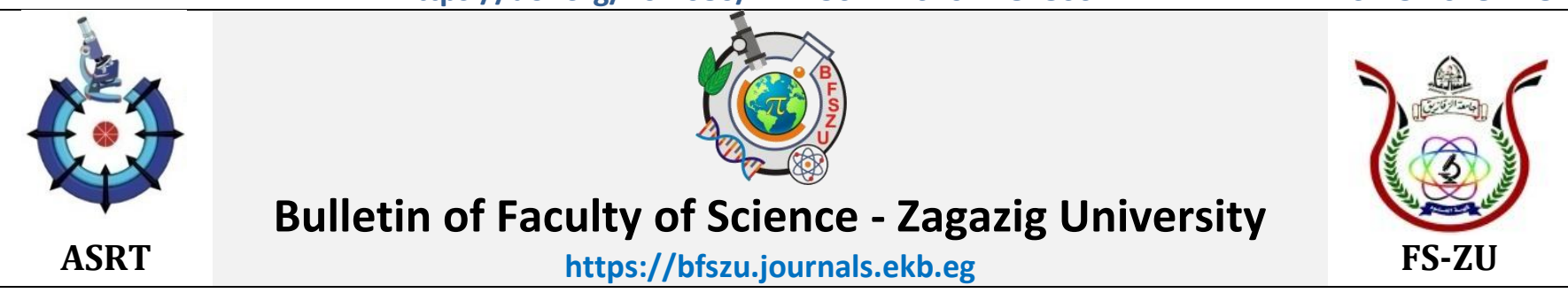

\title{
Characteristics of Gamma- Radiation Shielding for Raw Wood Materials Commonly Used in Egypt
}

\author{
Karriman Reda ${ }^{\mathbf{*}}$, Seham A. Said ${ }^{2}$, M. Fayez-Hassan², B. A. Tartor ${ }^{\mathbf{1}}$ and Ibrahim Bashter ${ }^{\mathbf{1}}$ \\ ${ }_{1}^{1}$ Physics Department, Faculty of Science, Zagazig University, Zagazig, Egypt \\ ${ }^{2}$ Experimental Nuclear Physics Department, NRC, EAEA, Cairo, Egypt
}

\section{ARTICLE HISTORY}

Received: May/2018

Revised: June/2018

Accepted: October $/ 2018$

\section{KEY WORDS}

Gamma radiation

shielding

Wood materials

Attenuation coefficients

Half value layer

\begin{abstract}
Nowadays, radiation shielding becomes vital. So, the main purpose of this study is to evaluate the characteristics and performance of six types of raw wood materials (Mosky, Zan, Contar, Balot, Orange tree and Aro) usually used in Egypt. Linear, mass attenuation coefficients and half value layer of wood species were measured at gamma-ray energy range from (30-2203 keV). Measurements were performed using aHPGe gamma spectrometer detector.The intensities of the emergent radiation were measured, when each of these woods were placed between the detector and radioactive sources $\left({ }^{133} \mathrm{Ba}-{ }^{226} \mathrm{Ra}\right)$. Analysis of results showed a strong correlation between wood density and attenuation coefficients. The lowest value of linear attenuation coefficient determined for each wood type is $0.040 \mathrm{~cm}^{-1}$ at energy $609 \mathrm{keV}$ for Mosky. On the other hand the highest value of linear attenuation coefficient at the same energy is, $0.078 \mathrm{~cm}^{-1}$ for Aro. So, Aro could selected and serve as a more favorable radiation shielding material against gamma ray.
\end{abstract}

*Corresponding Author: karrimanegy37@gmail.com

\section{INTRODUCTION}

Radiation shielding is essential for the protection of human and environment because the harmful effects of ionizing radiation can cause significant health hazards. With the development of technology, human health has started to be exposed to extra radiation which can damage the human cell (Betui 2012). Since the turn of the $20^{\text {th }}$ century human lifestyle and environment have changed due to the drastic increase in the number of radiation sources such as communication devices and high-energy medical equipment (Archer 1983). There are three basic rules in order to be protected from radiation. These are time of exposure to radiation, distance and shielding where the latter is the most important one (Akkurt et al. 2015; Özavci and Çetin 2016). Metal shields and non-metallic shields such as polymers are 
most often employed .Various materials, placed between a source and a detector can affect the amount of radiation transmitted from the source to the receptor (Woods 1982).

Lead, copper, mercury and concrete are the most commonly materials used for shielding. To shield a gamma ray, the linear attenuation coefficient should be known. The linear attenuation coefficient $\mu\left(\mathrm{cm}^{-1}\right)$ is defined as the probability of radiation interacting with the material per unit path length (Martin 2006). Traditional radiation-shielding materials such as lead, copper, mercury and concrete are not very suitable due to their high cost, high density, and adverse effects on the environment (Harish et al. 2009; Mann et al. 2015; Sayyed 2016; Mirji and Lobo 2017). Many different types of materials developed and tested which include biological

\section{THEORETICAL BACKGROUND}

When a gamma ray of intensity $\mathrm{I}_{0}$ is incident on a material of thickness $\mathrm{x}$, the attenuation of the neutron by the material is given by;

$$
I=I_{0} e^{-\mu x}
$$

where $I$ is the intensity after passage the thickness $\mathrm{x}$ and $\mu$ is the linear attenuation coefficient.

$$
\frac{\mu}{\rho}=\frac{1}{\rho x} \ln \frac{\mathrm{I} 0}{I}
$$

Where $\rho$ is the density of the wood species. The Half Value Layer (HVL) is the thickness of the material at which the initial radiation intensity is reduced by one-half and it is related to $(\mu)$ by:

$$
H V \mathrm{~L}=\frac{0.693}{\mu}
$$

materials, elements, compound, and some building materials (Chitralekha et al. 2005; Baltas et al. 2007; Akkurt 2009; Akkurt et al. 2006).. We use a wood as new shielding material due to its flexibility, light weight and low cost. Wood is extensively used as asource of chemicals for new materials and applications. Wood may be used as it is or after suitable chemical modification. Attenuation coefficients and density are characteristics that can best be used in sorting radiation attenuation abilities of wood species (Adebo and Ero2012). For this purpose the radiation shielding characteristics of six wood samples have been measured. For this investigation a wide gamma energy range from $30 \mathrm{keV}$ to $2203 \mathrm{keV}$ and HPGe detector gamma $\&$ X-ray detector with $70 \%$ efficiency was used.

Attenuation coefficients, density and half value layers are characteristics that can best be used in sorting radiation attenuation abilities of wood species.

\section{MATERIALS and METHODS}

Six wood samples, Mosky (Pine wood), Zan (Fagus wood), Contar, Balot (Ash wood), Orange wood and Aro (Oak wood), which usually used in Egypt are collected and dried in order to get rid of moisture under $20^{\circ} \mathrm{C}$ for an hour. The densities of wood samples were determined by measuring their masses and dimensions. Radioactive sources $\left({ }^{226} \mathrm{Ra}-{ }^{133} \mathrm{Ba}\right)$ were placed at a convenient distance from the sample. The gamma rays are allowed to pass through the first sample for a time of about 200 sec and the transmitted spectra are collected using CANBERRA MCA (4096 ch.) as shown in figure 1 . 


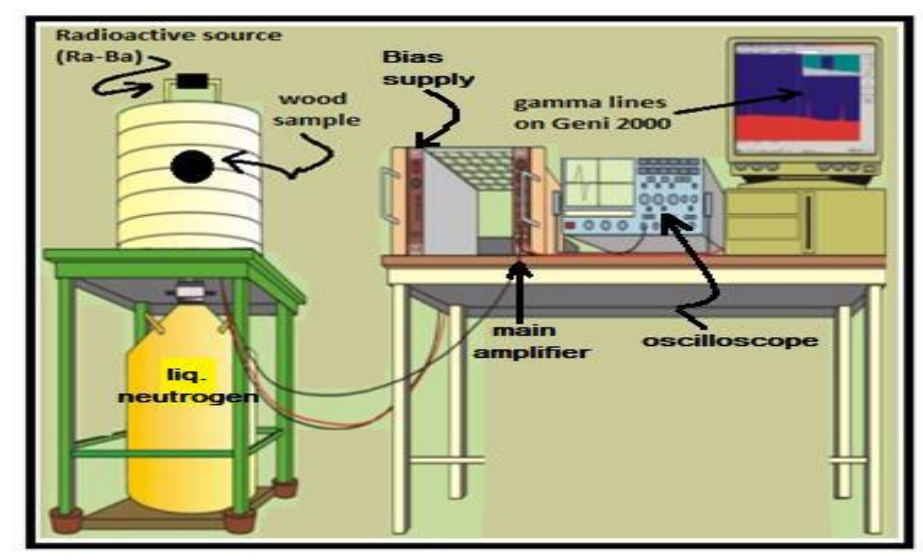

Fig. 1: Arrangements of HPGe Spectrometer System.

From the spectra, showed in figures 2 and 3 , the area of the gamma line at energies (30, $80,186,242,295,351,356,609,768,1120$, 1238,1764 and $2203 \mathrm{keV}$ ) which corresponding to the thickness of the absorber was determined. Then another sample was added to the earlier one and the spectrum taken. The same measurements were repeated for the rest of the samples. A graph between logarithms of the transmitted counts vs. the absorber thickness was drawn. The graphs were observed to be
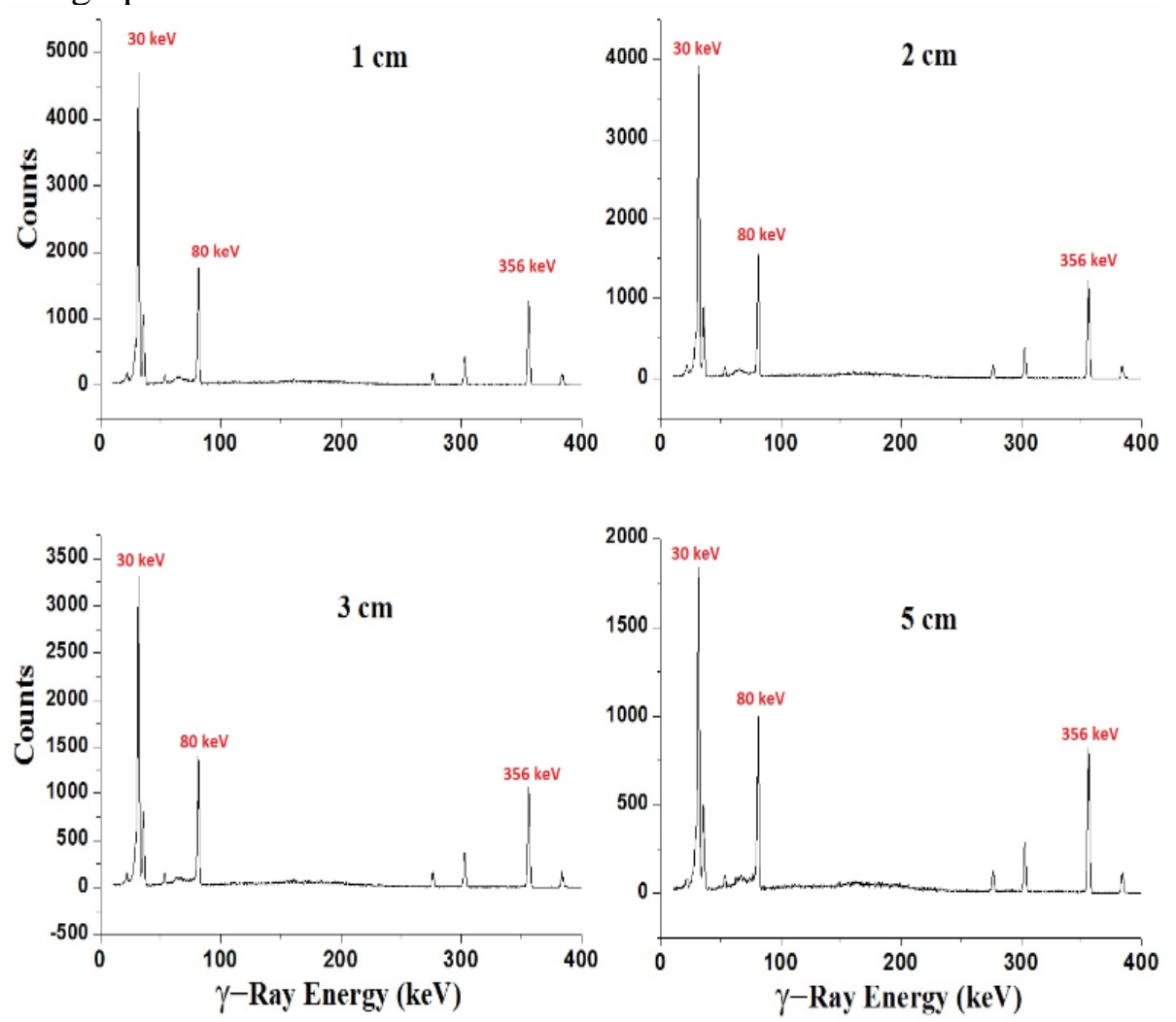

Fig. 2: Spectra of Ba-133 for Balot Samples. straight lines. Figure 4 represent the relation between linear attenuation coefficient $(\mu)$ of woods and gamma ray energy. From this figure, the linear attenuation coefficient value increases with the increasing of sample density for all gamma energies, except for Orange tree samples $\left(\rho=0.7418 \mathrm{~g} / \mathrm{cm}^{3}\right)$ which the $\mu$ value is lower than Balot $\left(\rho=0.7122 \mathrm{~g} / \mathrm{cm}^{3}\right)$ for all gamma energies due to the elementals composition of Orange tree samples. 

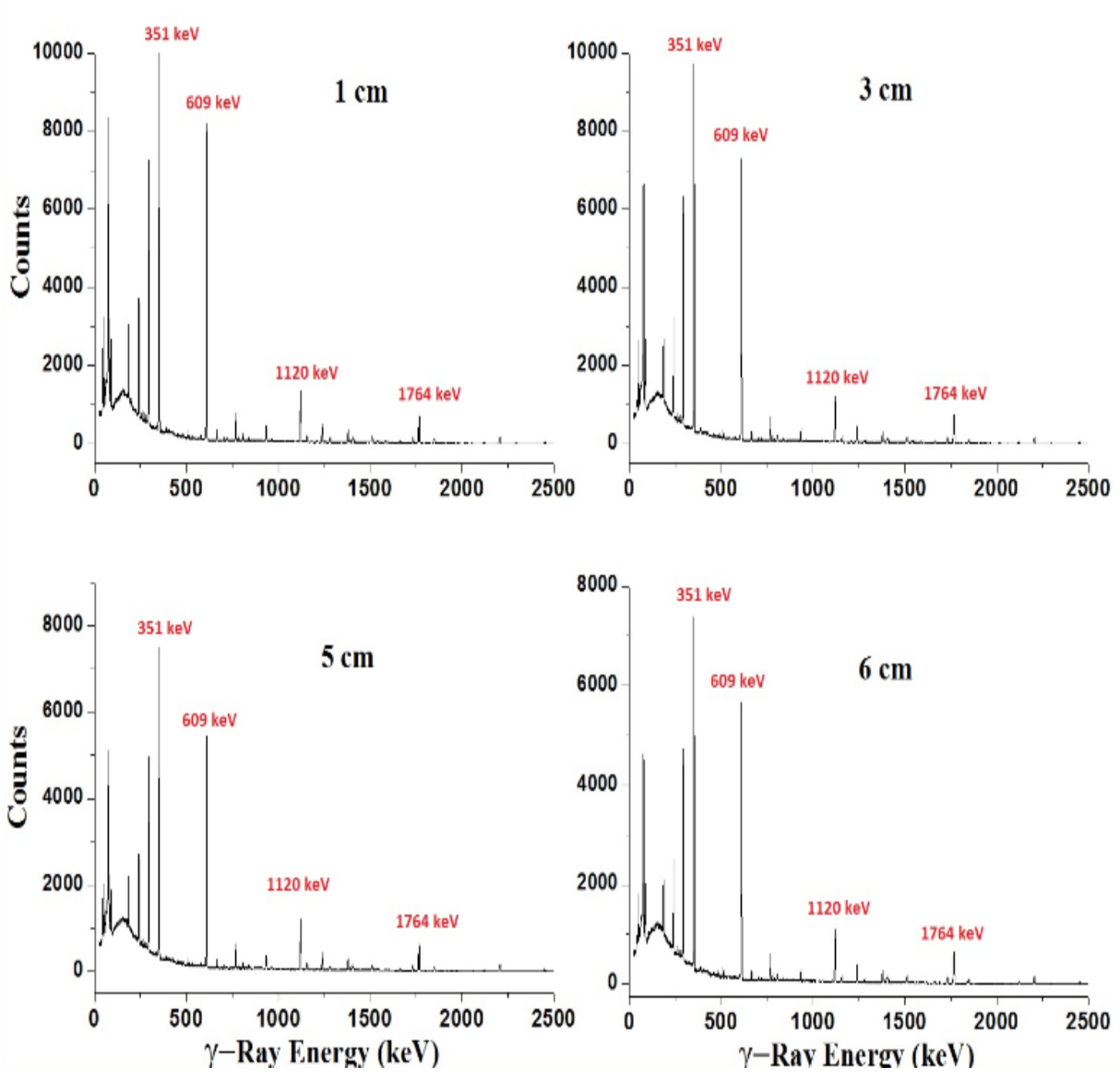

Fig. 3: Spectra of Ra-226 for Balot Samples.

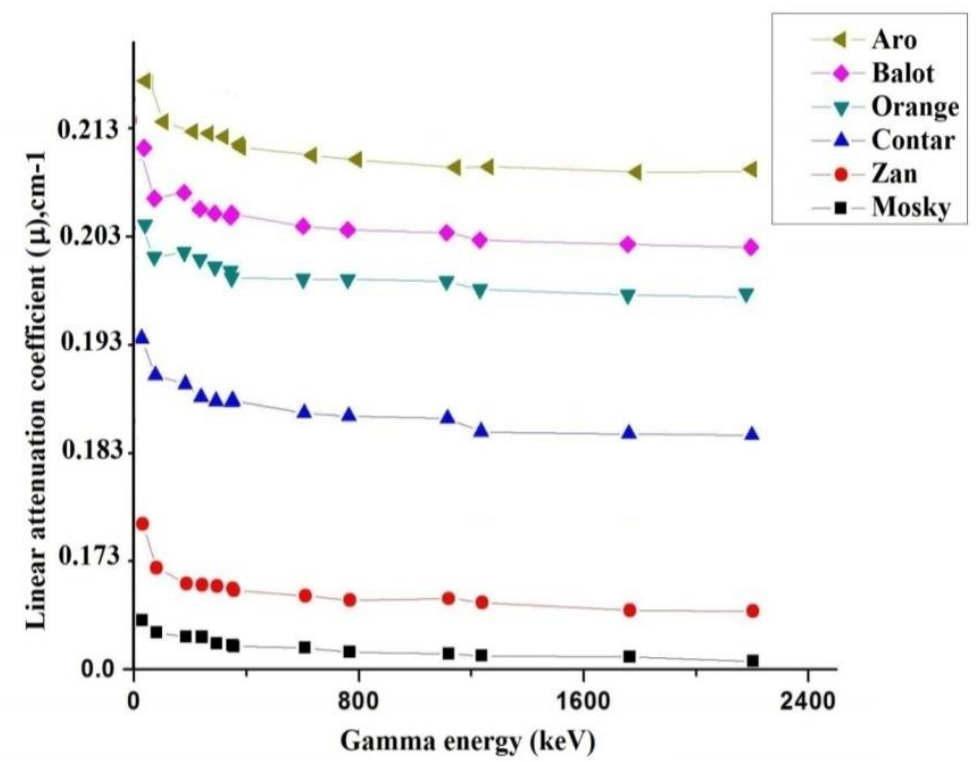

Fig. 4: Plot of linear attenuation coefficient $\left(\mathrm{cm}^{-1}\right)$ against gamma-ray energy $(\mathrm{keV})$ for wood samples. 


\section{RESULTS and DISCUSSIONS}

Figures 5 and 6 , represent the relation between $\ln \left(\mathrm{I} / \mathrm{I}_{\mathrm{o}}\right)$ and wood sample thickness for the lowest gamma-ray energy $30 \mathrm{keV}$ and the highest gamma-ray energy $2203 \mathrm{keV}$, respectively. Similar figures were plotted for all remains gamma energies $(80,186,242,295$, 351, 356, 609, 768, 1120, 1238 and $1764 \mathrm{keV}$ ) from which the linear attenuation coefficient $(\mu)$ was determined and listed in Table 1.

We can notice that Aro wood has the highest attenuation coefficient so, it is the best attenuator for gamma rays and it is considered as a good material used for radiation shielding and construction of attenuating material. On the other side Mosky wood has the lowest attenuation coefficient compared to all other wood samples so; it is a low quality material for gamma radiation shielding. The values of mass attenuation coefficient $(\mu / \rho)$ are calculated and are listed in Table 2.

Table 3 shows the calculation of half value layer (HVL) of various wood samples. The lowest half value layer of wood has the highest attenuation ability; this implies a good absorber of radiation. It can be seen that Aro wood, when compared with other woods, has the lowest half value layer and Mosky wood has the highest half value layer.

Table 1: Egyptian sample common names, Samples density $(\rho)$ and linear attenuation coefficient $\mu$ $\left[\mathrm{cm}^{-1}\right]$.

\begin{tabular}{|c|c|c|c|c|c|c|c|c|c|c|c|c|c|c|}
\hline \multirow{2}{*}{$\begin{array}{l}\text { wood } \\
\text { sample }\end{array}$} & \multirow{2}{*}{$\begin{array}{l}\text { Density } \\
\left(\mathrm{g} / \mathrm{cm}^{3}\right)\end{array}$} & \multicolumn{13}{|c|}{$\mathrm{E}(\mathrm{keV})$} \\
\hline & & 30 & 80 & 186 & 242 & 295 & 351 & 356 & 609 & 768 & 1120 & 1238 & 1764 & 2203 \\
\hline & & 0.091 & 0.069 & 0.000 & 0.000 & 0.048 & 0.045 & 0.043 & 0.040 & 0.032 & 0.020 & 0.025 & 0.024 & 0.0 \\
\hline Za & & 0.173 & 0.112 & 0.121 & 0.108 & 0.094 & 0.086 & 0.073 & 0.071 & 0.071 & 0.067 & 0.052 & 0.042 & 0.03 \\
\hline 0 & & 0.194 & 0.111 & 0.081 & 0.079 & 0.078 & 0.073 & 0.070 & 0.000 & 0.051 & 0.054 & 0.047 & 0.033 & 00 \\
\hline Balot ( & & 0200 & 0.137 & 0.118 & 0.115 & 0.100 & 0.055 & 0.090 & 0.075 & 0.067 & 0.052 & 0.054 & 0.044 & 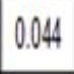 \\
\hline Or & & 0.204 & 0.136 & 0.120 & 0.096 & 0.088 & 0.088 & 0.090 & 0.067 & 0.061 & 0.056 & 0.032 & 0.028 & 0 \\
\hline Aro $(A)$ & 0.7579 & 0.216 & 0.129 & 0.139 & 0.109 & 0.102 & 0.096 & 0.101 & 0.078 & 0.071 & 0.071 & 0.052 & 0.044 & 0.03 \\
\hline
\end{tabular}

Table 2: Mass attenuation coefficient $\left(\mu / \rho, \mathrm{cm}^{2} / \mathrm{gm}\right)$ for wood samples.

\begin{tabular}{|c|c|c|c|c|c|c|c|c|c|c|c|c|c|c|}
\hline \multirow{2}{*}{$\begin{array}{l}\text { wood } \\
\text { sample }\end{array}$} & \multirow{2}{*}{$\begin{array}{l}\text { Density } \\
\left(\mathrm{g} / \mathrm{cm}^{3}\right)\end{array}$} & \multicolumn{13}{|c|}{$\mathrm{E}(\mathrm{keV})$} \\
\hline & & 30 & 8 & 10 & 242 & 295 & 351 & 356 & 609 & 68 & 1120 & 1238 & 1764 & 2203 \\
\hline & & 0.227 & & 51 & 0.150 & 0.121 & 0.112 & 0.107 & 0.101 & 180 & 0.072 & 0.063 & 159 & . \\
\hline Za & & 0.288 & 0. & 0.200 & 99 & 0.156 & 0.143 & 0.122 & 0.118 & 0.118 & 0.112 & 0.086 & 70 & 0 \\
\hline & & 0.295 & 0. & 20) & & 0.118 & 11 & 0.107 & 0.091 & 78 & 0.083 & 0.072 & 50 & \\
\hline Dallot & u & 0.293 & 0.192 & 0.160 & 0.161 & 0.153 & 0.133 & 0.126 & 0.105 & 0.094 & 0.074 & 0.075 & 0.061 & 0.0 \\
\hline $\mathrm{Or}$ & & 0.275 & 0.183 & 0.102 & 0.120 & 0.119 & 0.118 & 0.121 & 0.090 & 0.082 & 0.076 & 0.044 & 0.038 & \\
\hline Aro $1 \mathrm{~A}$ & & 0.285 & 0.170 & 0.184 & 0.144 & 0.134 & 0.126 & 0.133 & 0.102 & 0.094 & 0.094 & 0.069 & 0.059 & 0.0 \\
\hline
\end{tabular}


Table 3: Half value layer (HVL, cm) for wood samples.

\begin{tabular}{|c|c|c|c|c|c|c|c|c|c|c|c|c|c|c|}
\hline \multirow{2}{*}{$\begin{array}{l}\text { wood } \\
\text { sample }\end{array}$} & \multirow{2}{*}{$\begin{array}{l}\text { Density } \\
\left(\mathbf{g} / \mathrm{cm}^{3}\right)\end{array}$} & \multicolumn{13}{|c|}{$\mathrm{E}(\mathrm{keV})$} \\
\hline & & 30 & 80 & 186 & 242 & 295 & 351 & 356 & 609 & 768 & 1120 & 1238 & 1764 & 2203 \\
\hline Mosky (M) & 0.4001 & 7.64 & 10.12 & 11.49 & 11.57 & 14.32 & 15.47 & 16.15 & 17.20 & 21.66 & 24.06 & 27.50 & 29.49 & 44.14 \\
\hline $\operatorname{Zan}(Z)$ & 0.6010 & 4.00 & 6.18 & 5.76 & 6.43 & 7.40 & 8.05 & 9.44 & 9.73 & 9.80 & 10.28 & 13.38 & 16.54 & 18.38 \\
\hline $\operatorname{Contar}(\mathrm{C})$ & 0.6558 & 3.58 & 6.24 & 8 & 8.75 & 8.93 & 9.56 & 9.91 & 11.59 & 13.59 & 12.76 & 14.71 & 21.19 & 22.00 \\
\hline Balot(B) & 0.7122 & 3.32 & 5.07 & 5.86 & 6.03 & 6.36 & 7.33 & 7.73 & 9.25 & 10.37 & 13.23 & 12.91 & 15.86 & 15.71 \\
\hline Orange( 0 ) & 0.7418 & 3.39 & 5.10 & 5.78 & 7.26 & 7.84 & 7.92 & 7.72 & 10.37 & 11.34 & 12.29 & 21.46 & 24.84 & 27.72 \\
\hline $\operatorname{Aro}(A)$ & 0.7579 & 3.21 & 5.36 & 4.96 & 6.35 & 6.83 & 7.26 & 6.86 & 8.93 & 9.75 & 9.75 & 13.23 & 15.61 & 17.6 \\
\hline
\end{tabular}
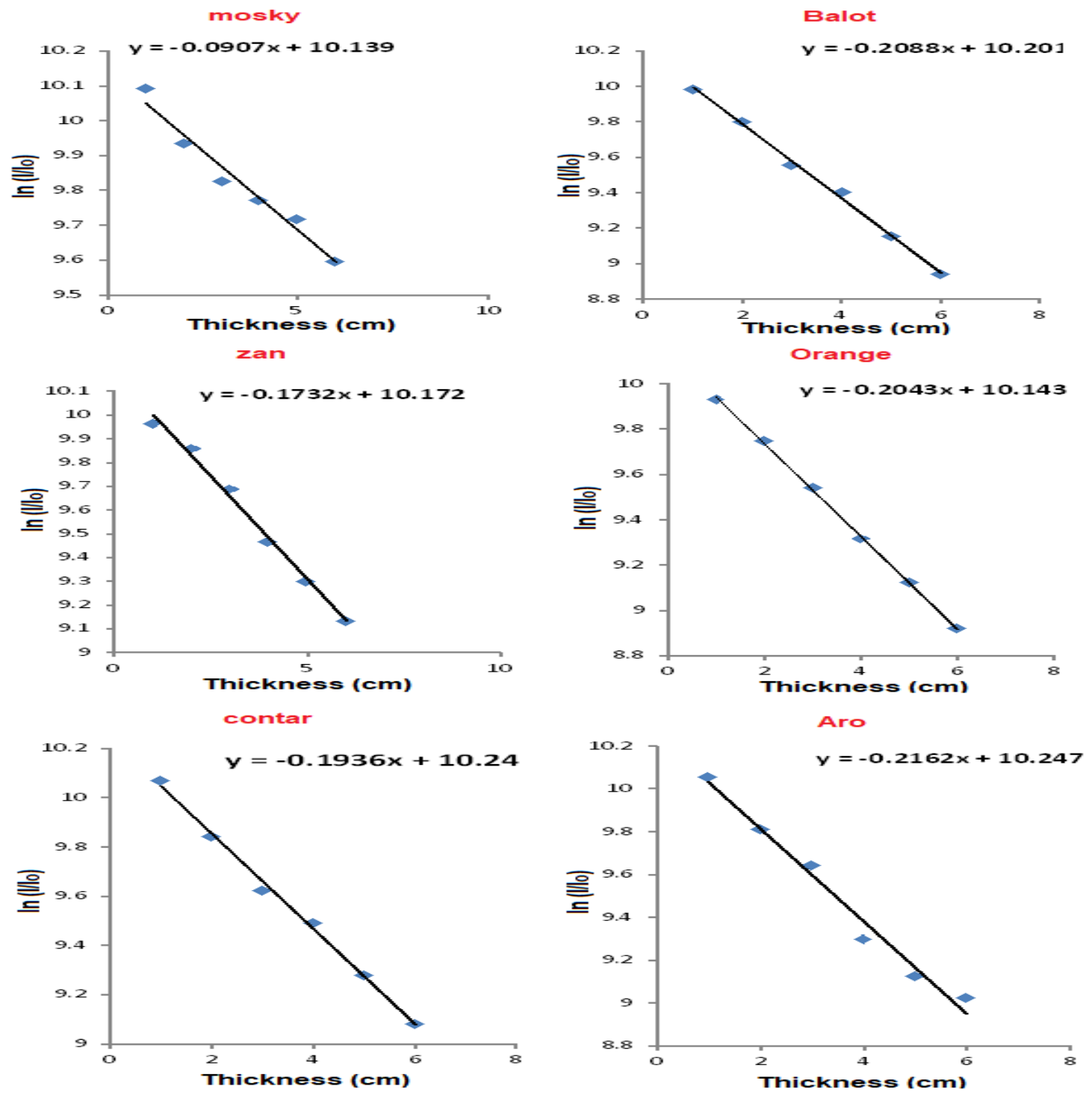

Fig. (5): Plot of $\ln \left(\mathrm{I}_{\mathrm{o}} / \mathrm{I}\right)$ against wood sample thickness for $30 \mathrm{KeV}$ gamma-ray energy. 

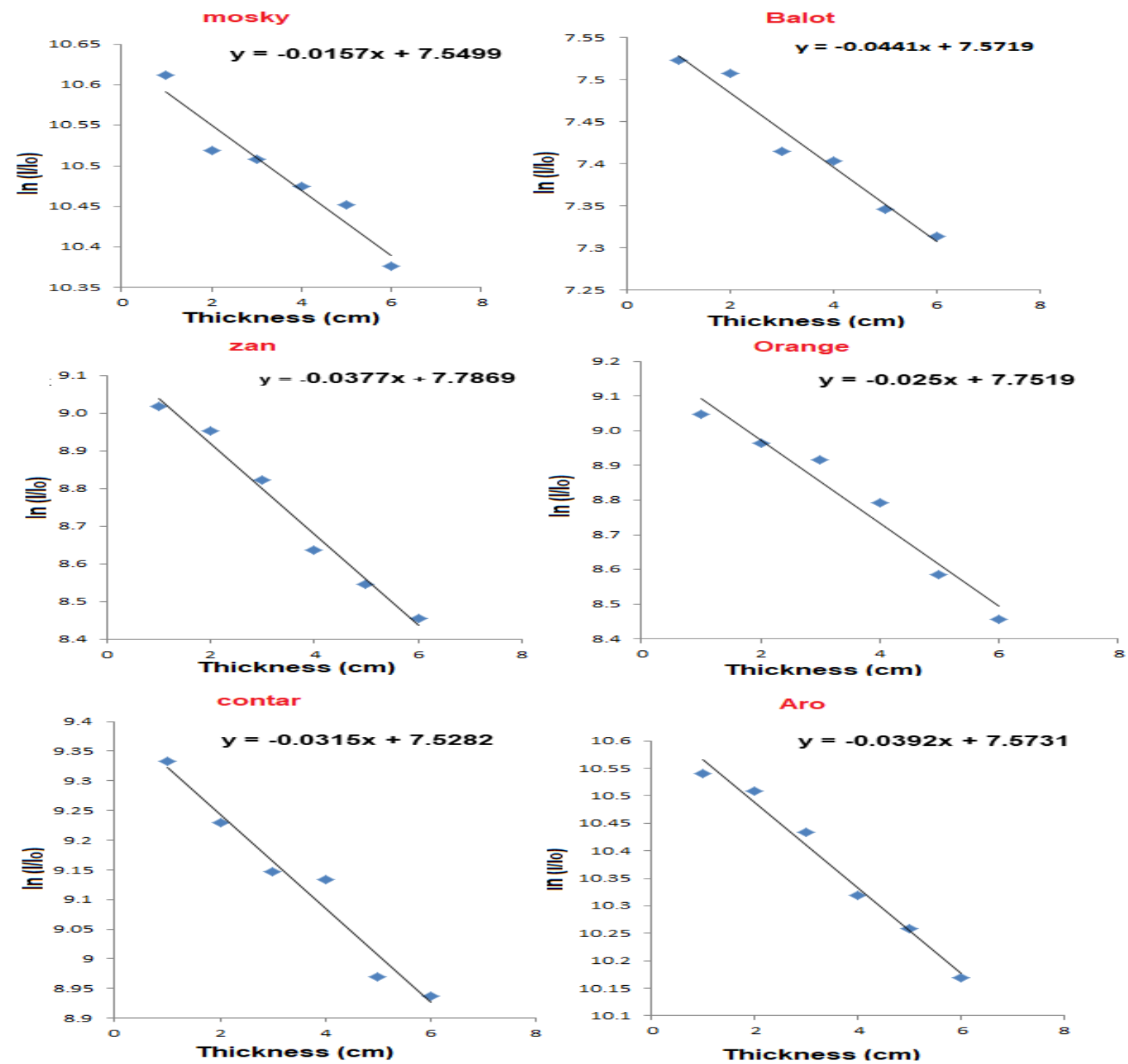

Fig. (6): Plot of $\ln \left(\mathrm{I}_{\mathrm{o}} / \mathrm{I}\right)$ against wood sample thickness for $2203 \mathrm{KeV}$ gamma-ray energy.

\section{CONCLUSION}

Radiation shielding is an important issue so, many researchers have been done in this field and also it should be continued. The locally available Egyptian Mosky, Zan, Aro, Contar, Balot and Orange tree wood samples have great economic potential for use as a gamma radiation shielding. The attenuation coefficients; linear attenuation coefficient $(\mu)$, mass attenuation coefficient $(\mu / \rho)$ and half value layer (HVL) measured in this study reflects the good quality of these locally shielding materials (tables 1-3). These coefficients can be effectively used for practical shielding calculations and are found to be highly dependent on the thickness and density of the shielding materials. It is found that attenuation coefficient, for the investigated wood samples, inversely proportional with photon energy and directly proportional with density of wood. It 
was observed that in terms of radiation shielding Aro samples were more suitable, than other tested wood samples, due to its high density $\left(0.757 \mathrm{~g} / \mathrm{cm}^{3}\right)$. These materials can be effectively employed as the gamma ray shields nearby the radiation installations to reduce the produced radiations to the permissible level.

\section{REFERENCES}

1. Adebo B A and Ero F A, "Determination of $\gamma$-Radiation Shielding Characteristics of some Woods in Western Nigeria", International Archive of Applied Sciences and Technology, vol.3, 14-20, (2012).

2. Akkurt I, "Effective Atomic and Electron Numbers of Some Steels at Different Energies". Ann Nucl Energy, vol.36(11-12), 1702-1705, (2009).

3. Akkurt I, Basyigit C, Kilincarslan S, Mavi B, Akkurt A, "Radiation Shielding of Concretes Containing Different Aggregates", Cement Concr Compos, vol.28(2), 153-157, (2006).

4. Akkurt I, Emikönel S, Akarslan F, Günoglu K, Kilinçarslan S, Üncü IS," Barite Effect On Radiation Shielding Properties of Cotton Polyester Fabric", ActaPhys Pol A 128:53, (2015).

5. Archer S C, "Medical X-ray and Gamma ray Protection for Energies up to $10 \mathrm{MeV}$ : Structural Shielding Design and Evaluation", National Council on Radiation Protection and Measurements", (1983), NCRP Report (1976).

6. Baltas H, Celik S, Cevik U, Yanmaz E, "Measurement of Mass Attenuation Coefficients and Effective Atomic Numbers for Mgb2 Super Conductor Using X-Ray Energies", RadiatMeas, vol.42, 55-60, (2007).

7. Betui M, "Experimental Investigation Of $\gamma$-Ray Attenuation Coefficient For Granite", Annals of Nuclear Energy, vol.44, 22-25, (2012).

8. ChitralekhaKerur BR, Lagare MT, Nathuram R, Sharma DN, "Mass attenuation coefficients of saccharides for low-energy Xrays", RadiatPhysChem, vol.72, 1-5, (2005).

9. Harish V, Nagaiah N, Prabhu TN, Varughese KT, "Preparation and Characterization of Lead Monoxide Filled Unsaturated Polyester Based Polymer
Composites for Gamma Radiation Shielding Applications", J ApplPolymSci, vol.112, 15031508, (2009).

10. Martin J E, "Physics for Radiation Protection", WILEY- VCH Verlag GmbH \&Co.KGaA, Weinheim, $2^{\text {nd }}$ Edition, (2006).

11. Mann KS, Rani A, Heer MS, "Shielding Behaviors of Some Polymer and Plastic Materials for Gamma-Rays".RadiatPhysChem, vol.106, 247-254, (2015).

12. Mirji R, Lobo B, "Computation of The Mass Attenuation Coefficient of Polymeric Materials at Specific Gamma Photon Energies", RadiatPhysChem, vol.135, 32-44, (2017).

13. Özavci S, Çetin B, "Determination of Radiation Attenuation Coefficients in Concretes Containing Different Wastes", ActaPhys Pol A 130:316, (2016).

14. Archer SC, "Medical X-ray and Gam-ma ray Protection for Energies up to $10 \mathrm{MeV}$ : Structural Shielding Design and Evaluation", National Council on Radiation Protection and Measurements", (1983), NCRP Report (1976).

15. Sayyed MI, "Investigation of Shielding Parameters for Smart Polymers", Chin J Phys, vol.54, 408-415, (2016).

16. Woods J," Computational Methods in Reactor Shielding", Pergamon, New York, (1982). 